\title{
O processo da linguagem escrita de alunos com dificuldades de aprendizagem em
}

\section{tempos de ensino remoto}

\author{
The written language process of students with learning difficulties in remote teaching times \\ El proceso del lenguaje escrito de los alumnos con dificultades de aprendizaje en tiempos de \\ enseñanza a la distancia
}

Recebido: 31/01/2022 | Revisado: 05/02/2022 | Aceito: 13/02/2022 | Publicado: 19/02/2022

\author{
Cristina Ferreira Acencio \\ ORCID: https://orcid.org/0000-0002-2642-5600 \\ Universidade Estadual de Maringá, Brasil \\ E-mail: crisacencio3@gmail.com \\ Elsa Midori Shimazaki \\ ORCID: https://orcid.org/0000-0002-2225-5667 \\ Universidade Estadual de Maringá, Brasil \\ E-mail: emshimazaki@uem.br
}

\begin{abstract}
Resumo
A presente pesquisa tematiza a escrita e a reescrita como instrumento para o desenvolvimento de funções psicológicas superiores de alunos com dificuldades de aprendizagem e tem como objetivo compreender a escrita e a reescrita de texto como mediadoras no desenvolvimento das funções psicológicas superiores em alunos com dificuldades do Ensino Fundamental I. Utilizamos como instrumentos a escrita e a reescrita de texto, a partir de uma revisão orientada pela professora. Para atender ao objetivo do estudo, realizamos uma pesquisa qualitativa, por meio de estudo de caso, com oficinas de intervenção pautadas nos pressupostos da teoria Histórico-Cultural. Conduzimos essas intervenções com cinco alunos do $3^{\circ}$ ano e do $4^{\circ}$ ano do Ensino Fundamental que possuem o diagnóstico de dificuldades de aprendizagem. A partir do gênero textual Fábula, realizamos produções textuais revisadas pela professora e reescritas pelos alunos, durante os meses de junho a agosto de 2020, de forma remota em virtude da pandemia. Verificamos, após a análise dos dados coletados, que os procedimentos de escrita e reescrita de texto contribuíram para a mobilização da atenção, memória e linguagem dos alunos com dificuldades de aprendizagem, mas como aplicamos de forma remota, não obtivemos o resultado esperado porque a falta da presença do professor como mediador no momento da realização das atividades acarretaram em prejuízos para os alunos que foram auxiliados por seus familiares.
\end{abstract}

Palavras-chave: Funções psicológicas superiores; Escrita de texto; Reescrita de texto; Dificuldades de aprendizagem.

\begin{abstract}
The present research approaches writing and rewriting as a tool for the development of higher psychological functions of students with learning difficulties and it aims to comprehend the writing and rewriting as mediators in the development of higher psychological functions in students with teaching difficulties of students from Elementary School. We applied the writing and rewriting of text as instruments, based on a review guided by the teacher. To meet the goal of the study, we carried out a qualitative research, through a case study, with intervention workshops based on the assumptions of the Historical-Cultural Theory. We conducted these interventions with five students from the 3rd and 4th grades from the Elementary School who had a diagnosis on learning difficulties. From the textual genre Fable, we carried out textual productions reviewed by the teacher and rewritten by the students, during the months from June to August 2020, remotely due to the pandemic. We verified, after analyzing the collected data, that the writing and rewriting procedures of text contributed to the mobilization of the required attention, memory and language of students with learning difficulties, but as we applied it remotely, we did not obtain the expected result because of lack of the physical presence of the teacher as a mediator at the time of the fulfillment from the activities resulted in losses for the students who were helped at home by their own families.
\end{abstract}

Keywords: Higher psychological functions; Writing; Rewriting; Learning difficulties.

\section{Resumen}

La presente investigación tematiza la escrita y reescritura como herramienta para el desarrollo de funciones psicológicas superiores de estudiantes con dificultades de aprendizaje y tiene como objetivo comprender la escrita y reescritura de texto como mediadores en el desarrollo de funciones psicológicas superiores en alumnos con dificultades de enseñanza de la escuela primaria. Utilizaron como instrumentación la escrita y la reescritura de textos, 
empezando por una revisión guiada por el maestro. Para cumplir con el objetivo del estudio, realizamos una investigación cualitativa, a través de un estudio de caso, con oficinas de intervención basados en los presupuestos de la teoría Histórico Cultural. Realizamos estas intervenciones con cinco estudiantes del tercer y cuarto grado de Enseñanza Básica que tenían un diagnóstico de dificultades de aprendizaje. En el género textual Fábula, realizamos producciones textuales revisadas por el maestro y reescritas por los estudiantes, durante los meses de junio a agosto de 2020, de forma remota por cuenta de la pandemia. Verificamos, pronto al analizar los datos recolectados, que los procedimientos de escrita y reescritura de texto aportaron por la movilización de la atención, la memoria y el lenguaje de los estudiantes con dificultades de aprendizaje, pero al aplicarlos de forma remota, no obtuvimos el resultado esperado debido a la falta de la presencia física del maestro como mediador al momento de realizar las actividades resultó en pérdidas para los estudiantes quienes fueron auxiliados en casa por sus familias. Palabras clave: Funciones psicológicas superiores; Escrita; Rescritura; Dificultades de aprendizaje.

\section{Introdução}

O presente artigo faz parte da pesquisa desenvolvida na dissertação da autora, que tematiza a escrita e a reescrita como instrumentos para o desenvolvimento das funções psicológicas superiores dos alunos com dificuldades de aprendizagem inseridos no $3^{\circ}$ e nos $4^{\circ}$ anos do Ensino Fundamental das séries iniciais, apresentado ao programa de pós-graduação em Educação da Universidade Estadual de Maringá.

Ao trabalharmos a produção de texto com esses alunos, surgiram questionamentos como: As propostas de produção textual propiciavam a escrita de textos coerentes que atendessem à função social e interativa da língua e se mobilizavam a atenção, a memória e a linguagem em alunos com dificuldades de aprendizagem? Como a escrita e a reescrita de texto contribuem no desenvolvimento de funções psicológicas superiores em alunos com dificuldades de aprendizagem do Ensino Fundamental? Para responder tais questionamentos, desenvolvemos a pesquisa com o objetivo de compreender a escrita e a reescrita de texto como mediadoras no desenvolvimento das funções psicológicas superiores em alunos com dificuldades do Ensino Fundamental series iniciais.

No projeto inicial, a coleta de dados seria de forma presencial, todavia, em função da pandemia causada pela Covid19, com início em dezembro de 2019, foi realizada de forma remota. A pandemia da covid-19, trouxe desafios e consequências aos diferentes segmentos da sociedade à saúde, à política, à economia e à educação. Na educação, os professores, os alunos e a família habituados à aula presencial, tiveram que se reorganizar adotando salas com ambientes virtuais, diferentes aplicativos, usos de novas tecnologias, uso de computadores e celulares passaram de forma mais efetiva, a ser a principal ferramenta do trabalho pedagógico.

Nessa nova rotina os alunos tiveram que se adaptar aos estudos em casa, uns por meio da televisão, outros que tinham acesso aos aparelhos eletrônicos passaram a realizar suas tarefas de ensino e aprendizagem por eles, conversas virtuais, para atender as necessidades devido às restrições sociais. No aspecto educacional a pandemia, impediu que crianças fossem às escolas, tendo seus estudos orientados na maioria das vezes por familiares em casa, os quais também apresentam dificuldades na hora de mediar as atividades escolares.

\section{Linguagem Escrita e a Internalização das Funções Psicológicas Superiores}

$\mathrm{Na}$ abordagem Histórico-Cultural, Vygotsky, Luria e Leontiev (2010) e Luria (1992) ressaltam que o desenvolvimento humano é produto da cultura e da história, pois são formas mediadas por signos e instrumentos que acontecem primeiramente na relação entre os sujeitos sociais e históricos que, posteriormente, é internalizada pelo sujeito com a mediação da linguagem e da cultura.

Nesse contexto, o instrumento tem a função de servir como condutor da ação humana sobre o objeto da atividade, ou seja, é um meio pelo qual a atividade humana externa é dirigida para o controle e para o domínio da natureza. E é pelo emprego dos signos que o homem controla a operação psicológica, ou seja, o signo é um meio da atividade interna dirigido 
para o controle do próprio indivíduo. O signo tem a função de atuar sobre o psiquismo humano modificando-o (Vygotsky, 2007).

Os novos instrumentos de trabalho ocasionam novas estruturas sociais e o pensamento suscita o aparecimento de estruturas cognitivas, caracterizadas como funções psicológicas superiores. Essas funções são atividades mentais internas, organizadas em sistemas funcionais, emergindo da atividade prática desenvolvida na sociedade humana com base no trabalho (Leontiev et al., 2005).

As funções psicológicas superiores que possibilitam, aos humanos, a iniciação no mundo dos símbolos, mediada pelas interações sociais, neste estudo destacamos: a atenção, a linguagem e a memória. Fundamentados na teoria Histórico-Cultural de Vygotsky (2007), Luria (2010) e Leontiev (1992), postulamos a língua escrita como um desenvolvimento de funções psicológicas superiores, pois exige consciência, abstração e controle.

A atenção corresponde ao caráter direcional e à seletividade dos processos mentais, fator responsável pelo processo que mantém uma vigilância sobre o curso preciso e organizado da atividade mental (Luria, 1981 \& Vygostky, 1996). Por isso, a atenção organiza e prepara o homem à atividade e, consequentemente, à solução de problemas. O sujeito recebe muitos signos que são estímulos artificiais (sons, gestos, imagens, linguagem), seleciona os que the interessa e faz associações para suas atividades de pensamento (Vygotsky, $2001 \&$ Luria, 1992).

A possibilidade de combinar esses estímulos dos campos visuais presente e passado em um único campo de atenção leva à reconstrução de outra função fundamental psicológica superior, a memória (Vygotsky, 1996). A função básica da memória é organizar o pensamento de forma sistematizada, para que indivíduo possa reter, recordar e reproduzir os conteúdos. Assim, a real função da memória é de organizar, não só a ação presente, mas também a ação futura (Vygotsky; Luria, 1996 \& Vygotsky, 2001).

Vygotsky (1988), considera a escrita simbólica uma construção culturalmente elaborada, não apenas uma atividade motora, pois faz parte de um sistema de símbolos e signos cuja dominação remete a um ponto crítico no desenvolvimento cultural da criança, e não deve ser alcançado de forma mecânica, mas de um longo processo de funções comportamentais complexas.

No que se refere a produção da escrita no âmbito escolar, Fiad e Mayrink-Sabinson (2001), Sercundes (2004) e Menegassi e Gasparotto (2020), expõem que a escrita é uma atividade contínua, em que a primeira versão de um texto nunca é um produto pronto e acabado, mas resultado de reflexões, revisões, releituras e reescritas, que acontece por meio de um processo participativo e recíproco entre professor e aluno.

Menegassi (2016) fundamentado, sobretudo, nos estudos de Geraldi (1996), Fiad e Mayrink-Sabinson (2001) e Sercundes (2004) ressalta que o ensino da produção textual escrita em língua materna no decorrer da história da educação brasileira, passou por várias concepções de escrita, sendo elas: a) escrita com foco na língua; b) escrita como dom/inspiração; c) escrita como consequência; d) escrita como trabalho.

A escrita, com o foco na língua, corresponde à internalização do pensamento em relação às regras gramaticais e à norma padrão de escrita. A escrita como dom ou inspiração determina que o aluno busca informações nos seus conhecimentos acerca do texto e, para isso, basta que tenha o "dom divino" ou a "inspiração divina" para produzi-lo, em uma recorrência a poderes espirituais divinos para escrever, conforme sustentavam os antigos escribas dos templos religiosos.

Nessa abordagem, escrever, para o aluno, é apenas combinar informações divulgadas pelos meios de comunicação, sem qualquer discussão sobre o tema, habilidade decorrente de um dom, com o objetivo_de preencher os espaços livres de uma aula e manter o aluno ocupado, evitando que ele fique ocioso na sala de aula. 
A escrita como consequência acontece quando o trabalho realizado em sala de aula ou em extraclasse é feito de forma homogeneizada, por exemplo, o aluno é conduzido a uma pesquisa, a um debate, a assistir um filme ou a fazer um passeio ou visita e, na sequência, deve produzir um texto (Menegassi, 2010, 2016).

A escrita como trabalho por sua vez, passa pelas etapas do processo de planejamento, execução, revisão e reescrita (Menegassi, 2016 \& Beloti, 2016). A primeira etapa, como o nome já diz, consiste no planejamento de como o escritor produzirá seu texto, além de quais elementos linguístico-discursivos usará, fazendo o levantamento das informações e organizando suas ideias.

$\mathrm{Na}$ execução da escrita o escritor define, desenvolve e exemplifica as ideias e as informações levantadas no planejamento, buscando manter a unidade do texto e efetivamente realizar a escrita do texto. A revisão é o momento que o escritor, após escrever, faz a releitura de seu texto, pontuando quais aspectos formais e de conteúdo devem ser alterados. Essa etapa de revisão do texto pode ser realizada pelo próprio escritor, pelo professor ou por um colega de sala, sempre orientados pelo docente. A última etapa, é a_reescrita, onde o autor do texto observa os levantamentos dos aspectos a serem revisados e faz a reescrita da produção textual (Menegassi, 2016 \& Beloti, 2016).

O processo de revisão e reescrita, que leva a modificações e alterações no texto inicial, considera a escrita como "trabalho", porque demanda preparar, construir, revisar, reescrever e avaliar um texto, por isso ela é considerada como pertencente à abordagem processual-discursiva de escrita (Menegassi, 2016).

Além disso, é importante ressaltar que a produção escrita mobiliza funções psicológicas superiores, pois, ao escrever, o sujeito internaliza conceitos, elabora o pensamento e adquire novos conhecimentos. Garcez (1998) expõe que a escrita "Exige o desenvolvimento de atividades mentais extremamente complexas (as funções mentais superiores) tais como a memorização ativa, a atenção voluntária, as ações conscientemente controladas, o pensamento abstrato, a capacidade de generalização, o comportamento intencional, entre outras" (Garcez,1998, p. 80).

Nessa relação dialógica entre o escritor e a pessoa com quem o produtor do texto se dirige para argumentar, comentar e criticar, o professor é visto como o mediador que ajuda o aluno na produção textual. Assim, nesse processo de interação, as funções psicológicas superiores de atenção, memória e linguagem emergem e possibilitam que o aluno desenvolva a habilidade de produzir um texto, uma vez que, para realizar a produção textual, o aluno busca informações armazenadas em sua memória, a fim de dividi-las e organizá-las conforme as exigências do texto que produzirá.

O trabalho de revisão e reescrita de textos, no âmbito escolar, conforme Menegassi e Gasparotto $(2019$, p. 108), acontece a partir da interação entre professor e aluno "[...] como processo de significação, de internalização, de apropriação, de sistematização e de desenvolvimento de habilidades de escrita". Nessa perspectiva dialógica, o aluno vê o professor/mediador/revisor como seu colaborador para alcançar o objetivo comunicativo.

Menegassi e Gasparotto (2020), salientam que a prática de revisão textual realizada pelo professor trata-se de um processo que auxilia o desenvolvimento das habilidades de escrita e tem um caráter mediador, em que o professor auxilia o aluno, ampliando suas possibilidades ao reescrever seu texto.

É válido frisar que a reescrita não corresponde apenas à correção do texto ou em eliminar as formas erradas apresentadas na produção, mas também em "[...] tornar o texto mais interessante, adequá-lo melhor ao leitor, torná-lo mais enfático, enfim, objetivos que envolvem a exploração dos recursos expressivos da língua" (Fiad, 2006, p. 33).

Nesse contexto de revisão e reescrita, Menegassi e Gasparotto (2019) salientam que os apontamentos de revisão nem sempre são compreendidos pelo aluno de forma imediata, podendo responder a reescrita do texto de forma coesa com o que foi solicitado ou de forma gradativa, respondendo alguns aspectos pautados na revisão, ignorando, relembrando, internalizando e se apropriando do processo de elaboração do discurso escrito. 
Para que a revisão ocorra de forma interativa e dialógica, o professor, por meio de bilhetes alocados na margem ou no final do texto, além de comentar os desvios, elogia o trabalho do aluno, mantendo um diálogo junto ao sujeito autor e ao processo de aprendizado da prática de revisão e reescrita. Assim, a revisão configura-se num momento de troca, negociação e reflexão entre professor e aluno ou entre aluno e texto. Portanto, a reescrita depende inteiramente da efetividade da revisão e da resposta do produtor do texto (Menegassi, 2016 \& Menegassi \& Gasparotto, 2020).

\section{Metodologia}

O trabalho desenvolvido é uma pesquisa qualitativa do tipo estudo de caso, cujo objeto é uma unidade que se analisa profundamente as ciências humanas, pois possibilita ao investigador subsídios em relação ao fenômeno pesquisado com base na teoria Histórico-Cultural sobre um fenômeno contemporâneo dentro do seu contexto de vida real, destacando seu caráter de investigação (Yin, 2001).

A pesquisa que deu origem a este trabalho foi realizada com um grupo de 5 alunos, matriculados na Sala de Apoio em contraturno escolar (ACE), do $3^{\circ}$ e $4^{\circ}$ anos do Ensino Fundamental Anos Iniciais, de uma escola pública municipal, em uma cidade do Noroeste do Estado do Paraná. Os participantes foram selecionados juntamente com a professora, a orientadora, a supervisora e a diretora da escola. Sendo que dois participantes apresentam dificuldades de aprendizagem na leitura e na escrita e os outros três participantes possuem diagnóstico de Transtorno de Déficit de Atenção e Hiperatividade (TDAH).

Quadro 1 - Idade/série e diagnóstico dos sujeitos pesquisados.

\begin{tabular}{|l|l|l|l|}
\hline \multicolumn{1}{|c|}{ Sujeito } & \multicolumn{1}{c|}{ Ano } & \multicolumn{1}{c|}{ Diagnóstico } \\
\hline Sujeito 1 & $3^{\circ}$ ano & 8 anos & Dificuldades de aprendizagem \\
\hline Sujeito 2 & $3^{\text {o }}$ ano & 8 anos & Dificuldades de aprendizagem \\
\hline Sujeito 3 & $3^{\circ}$ ano & 9 anos & TDAH \\
\hline Sujeito 4 & $4^{\text {o }}$ ano & 9 anos & TDAH \\
\hline Sujeito 5 & $4^{\text {o }}$ ano & 10 anos & TDAH e Transtorno Específico da Aprendizagem. \\
\hline
\end{tabular}

Fonte: Autoras (2021).

O trabalho desenvolvido foi inserido no Projeto Educação intitulado "LINGUAGEM, LETRAMENTO E DIVERSIDADE", aprovado pelo Comitê Permanente de Ética em Pesquisa com Seres Humanos (COPEP), da Universidade Estadual de Maringá, por meio do parecer nº 3.765.908.

A pesquisa foi realizada no período de 25 de maio a 31 de agosto de 2020 em uma escola municipal do Noroeste do estado do Paraná. Os participantes da pesquisa foram cinco alunos que cursavam na época da coleta de dados o $3^{\circ}$ ano e o $4^{\circ}$ anos do Ensino Fundamental Anos Iniciais matriculados na sala de apoio em contraturno escolar. Dois dos participantes têm dificuldades de aprendizagem e três com diagnóstico de TDAH, conforme consta nos laudos médicos anexado as fichas individuais dos alunos. Os registros coletados da pesquisa foram de forma remota, feitos a distância, realizados na residência dos participantes, pois os alunos não podiam frequentar o ensino presencial na instituição escolar, a fim de evitar o contágio e atender as determinações da saúde acerca da COVID-19.

Os resultados obtidos são apresentados e discutidos, por meio de oficinas de interpretação textual, produção e reescrita realizadas de forma remota. As atividades foram elaboradas de modo que facilitasse a compreensão dos familiares que na maioria não apresentavam formação acadêmica suficiente para auxiliar os filhos com dificuldades de aprendizagem e eram os responsáveis para ler o comando das produções e ajudar as crianças nos encaminhamentos propostos nas tarefas escolares. 
Os dados coletados foram por meio de atividades impressas retiradas e devolvidas pelos responsáveis na escola. As atividades foram adaptadas com a escrita em letra maiúscula para auxiliar na leitura e na compreensão dos alunos e dos familiares. Optamos por trabalhar a fábula de Monteiro Lobato que é um autor cujas produções fazem parte do cotidiano do processo de ensino e aprendizagem do Ensino Fundamental Anos Iniciais.

\section{Resultados e Discussão}

No que antecede as oficinas de escrita e reescrita propusemos aos participantes com auxílio dos familiares, a leitura e interpretação textual da Fábula: O leão e o ratinho de Monteiro Lobato, também propusemos uma leitura comparativa da fábula com O leão e o ratinho do Esopo.

$\mathrm{Na}$ oficina de produção textual foi proposto a escrita individual da fábula "O leão e o ratinho" com objetivo de escrever um texto com sequência na exposição de ideias, coesão e coerência. Em se tratando do ensino remoto, as atividades foram realizadas sem a presença da pesquisadora professora, neste momento, junto ao enunciado da atividade foi mencionado aos familiares que lessem com a criança a fábula $\mathrm{O}$ leão e ratinho escrita por Esopo e a versão escrita por Monteiro Lobato trabalhadas em oficinas anteriores de interpretação textual e os participantes escrevessem um texto de acordo com sua compreensão. A seguir apresentamos as produções dos participantes.

\subsection{Descrição da Oficina de escrita}

O participante $1 \mathrm{fez}$ boa parte de seu texto uma transcrição da fábula do Esopo, apresentando alguns problemas de ordem ortográfica (por exemplo, "UMS”, “COMSIGIRAN", "PREMDEU”, "IMPLOROU”), de paragrafação e segmentação. Limitou se a fazer uma cópia da fábula, deixando de buscar na memória informações e estabelecer relações com suas experiências culturais. Isso revela as dificuldades e as fragilidades do ensino remoto, pois se as aulas fossem presenciais haveria a mediação do professor no momento da escrita. 
Research, Society and Development, v. 11, n. 3, e22111326385, 2022

(CC BY 4.0) | ISSN 2525-3409 | DOI: http://dx.doi.org/10.33448/rsd-v11i3.26385

Figura 1 - Produção textual do participante 1.

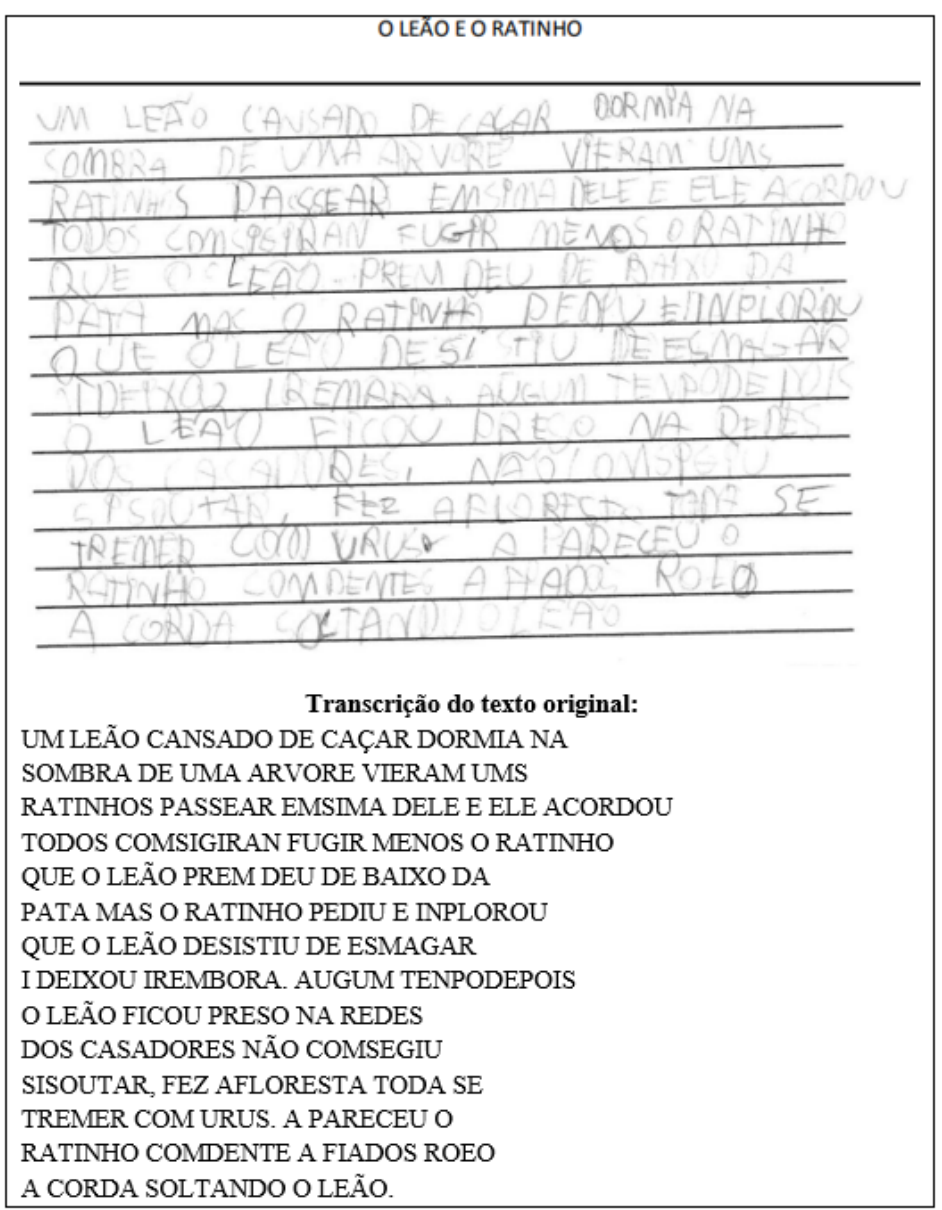

Fonte: Autoras (2021).

O participante 2 usou para iniciar o seu texto a expressão "era uma vez" em seu texto narrativo, termo usado nas literaturas infantis e escreveu detalhes sobre a história como o cansaço do leão de tanto caçar, as relações de conflito do ratinho e o leão desde o momento que é caçado até o momento que tornam amigos.

No texto, o participante colocou elementos apresentados nas atividades de compreensão e de interpretação textuais, acrescentou a narrativa expressões de seu cotidiano. Quando a criança passa a criar seus próprios estímulos evocadores para recordar sobre algo, evidencia-se que as funções superiores criaram estímulos artificiais ou signos (memória mediada), resultante dos processos psicológicos decorrentes do contexto sociocultural (Luria,1992).

Ademais, apresentou um desfecho diferente para a história, ao dizer que viraram amigos, o que demonstra um conceito socialmente construído, no qual os amigos se ajudam nos momentos conflitantes. A linguagem escrita do participante é baseada nas literaturas infantis, pois aparecem elementos comuns dos contos de fadas, o que possivelmente vem de uma memória internalizada.

Observamos ainda, nessa produção escrita, que o autor planejou como escreveria seu texto e utilizou-se da memória mediada utilizada nas oficinas anteriores e, também, organizou essas informações, buscando manter uma unidade e uma sequência lógica em sua produção (Menegassi, 2010 \& Beloti, 2016). 
Figura 2 - Produção textual do participante 2

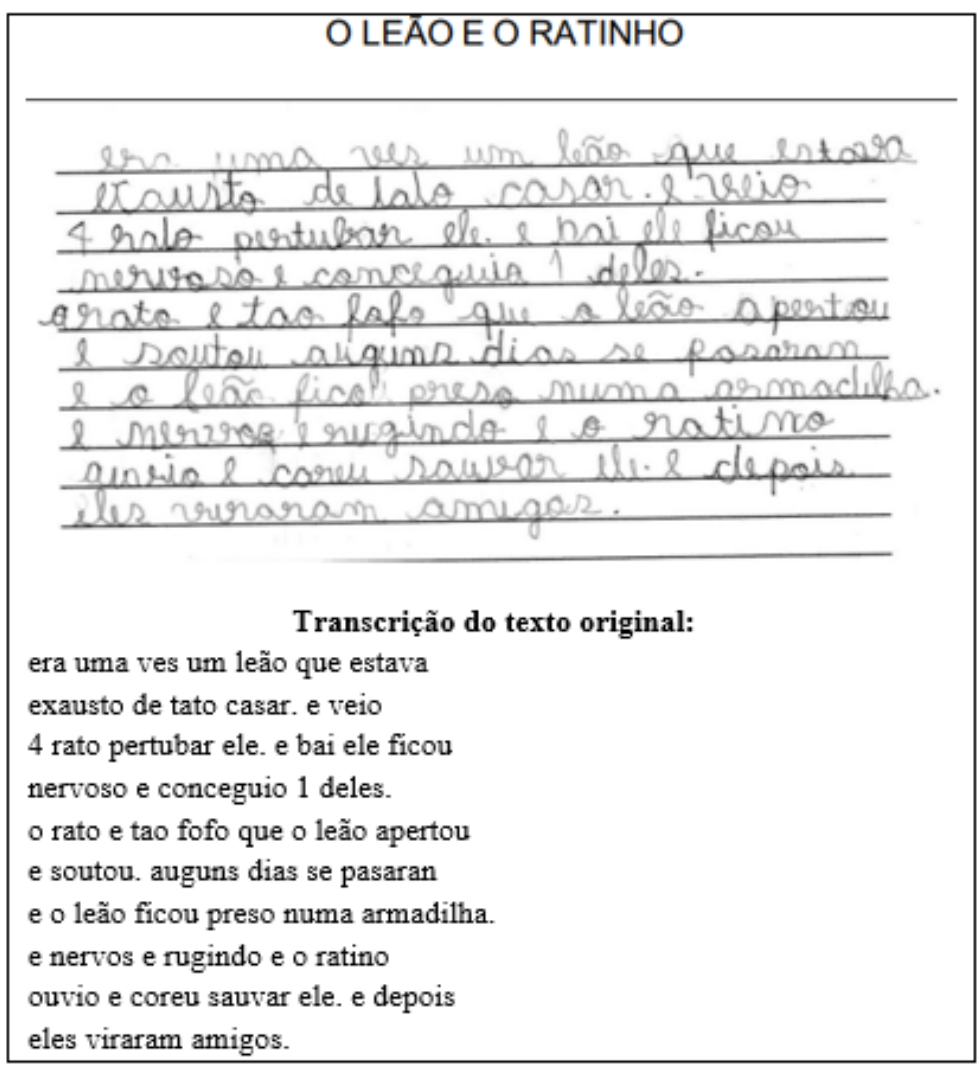

Fonte: Autoras (2021).

O participante 3 fez um parágrafo relatando partes da história de forma resumida como o fato do leão tratar bem o ratinho e justificou que, por ter sido bom com o ratinho, ele ajudou o leão. Outro ponto interessante do texto do participante foi no trecho que ele fez uma rasura na palavra "ajudou". Segundo Fiad (2006), as rasuras e as alterações feitas pela criança no texto revelam sua atividade reflexiva acerca da escrita.

Smolka e Goes (2008) corrobora ao inferir que quando as crianças cometem rasuras ou erros nas suas produções escritas isso significa que elas estão expressando as suas ideias, pois a aprendizagem da escrita envolve o conhecimento das letras, das palavras e das orações, além da organização textual para interagir com o outro leitor por meio da escrita.

Figura 3 - Produção textual do participante 3.

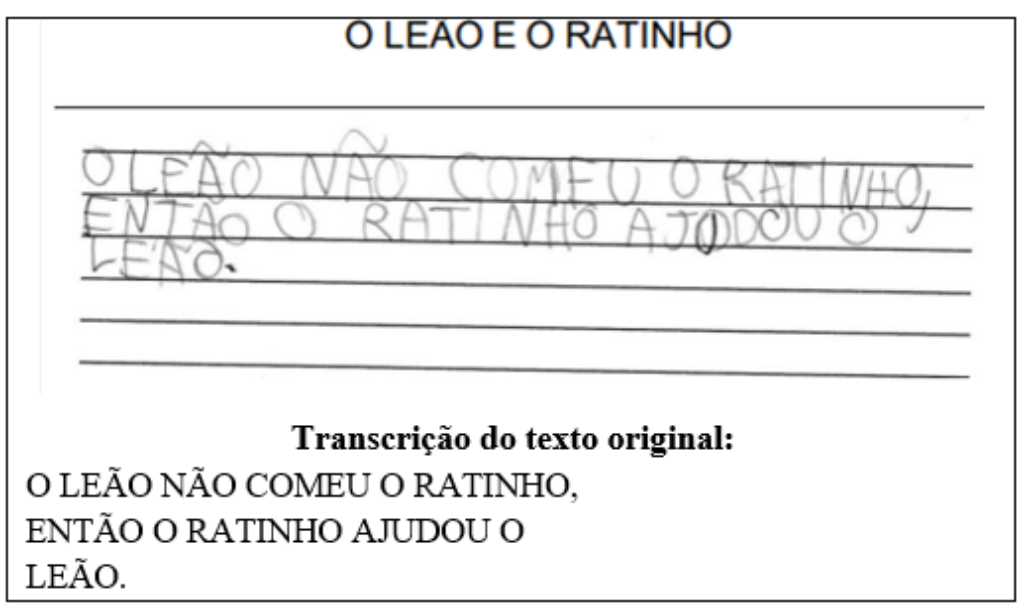

Fonte: Autoras (2021). 
O participante 4 iniciou a história de acordo com as suas respostas trabalhadas nas oficinas anteriores de interpretação textual, apresentou sequência de acontecimentos da fábula, escreveu a situação do ratinho ao sair do buraco e ficar preso nas patas do leão, apresentou detalhes sobre o conflito do ratinho como quando ficou preso entre as patas do leão: “os pelos em pé paralisado pelo terror". Demonstrou, ainda, resgate da memória relacionada à linguagem escrita e estabeleceu a função básica de organizar o pensamento, a fim de recordar e reproduzir os conteúdos obtidos das experiências anteriores (Vygostky, 2001).

Na sequência, o participante apresentou, no desfecho, a atitude do ratinho para com o leão e questionamentos internalizados nas atividades de comparação entre a Fábula do Esopo e a de Monteiro Lobato. Para que houvesse a retomada e a expansão das ideias no texto, propusemos, na etapa de revisão, apontamentos, questionamentos e comentários a respeito do texto do participante.

Figura 4 - Produção textual do participante 4.

O LEAO E O RATINHO
Transcrição do texto original:
$\begin{aligned} & \text { ao sair do buraco entre as patas avia um ratinho } \\ & \text { e os pelos en pé paralisado pelo terror ums } \\ & \text { dias depois ele ficou preso narede e tentava } \\ & \text { rasgar a rede e quanto mais se mexia ma- } \\ & \text { is ficava mais preso e o ratinho ajudou o le- } \\ & \text { ão. }\end{aligned}$

Fonte: Autoras (2021).

O participante 5, a princípio, segundo a família se recusou a fazer a atividade. Orientamos a responsável em deixar a criança bem tranquila para escrever, sem preocupação, com eventuais erros na escrita, pois, nesse momento, era preciso saber como era a sua escrita acerca da fábula. Após essa conversa, o participante apresentou poucos elementos e informações em relação às escritas anteriores, houve avanço ao escrever um texto com sequência e com algumas inferências, por exemplo, "com muito amo pela amizade o rato foi salvalo".

Segundo Benczik (2000), essas dificuldades vão desde os aspectos comportamentais até os aspectos cognitivos, possivelmente indicam que esse participante se frustra com facilidade, demonstrando resistência em realizar as tarefas escolares, principalmente as que envolvem esforço mental, que são vivenciadas como desagradáveis e acentuadamente aversivas.

$\mathrm{Na}$ escrita houve uma preocupação em descrever o conflito do ratinho e deixou de acrescentar outras informações que foram mencionadas nas atividades anteriores de leitura e interpretação textual. Para finalizar seu texto, escreveu a respeito do conflito do leão ao ficar preso nas cordas e acrescentou reflexões pessoais sobre o ensinamento da fábula, dizendo que, com muito amor pela amizade, o ratinho salvou o leão. Isso demonstra mobilização da memória e dos conceitos culturais já internalizados ao relacionar a retribuição do ratinho em ajudar o leão, o que indica que, para o aluno, o amor e a amizade envolvem ajuda em situações conflituosas. 
Figura 5 - Produção textual do participante 5.

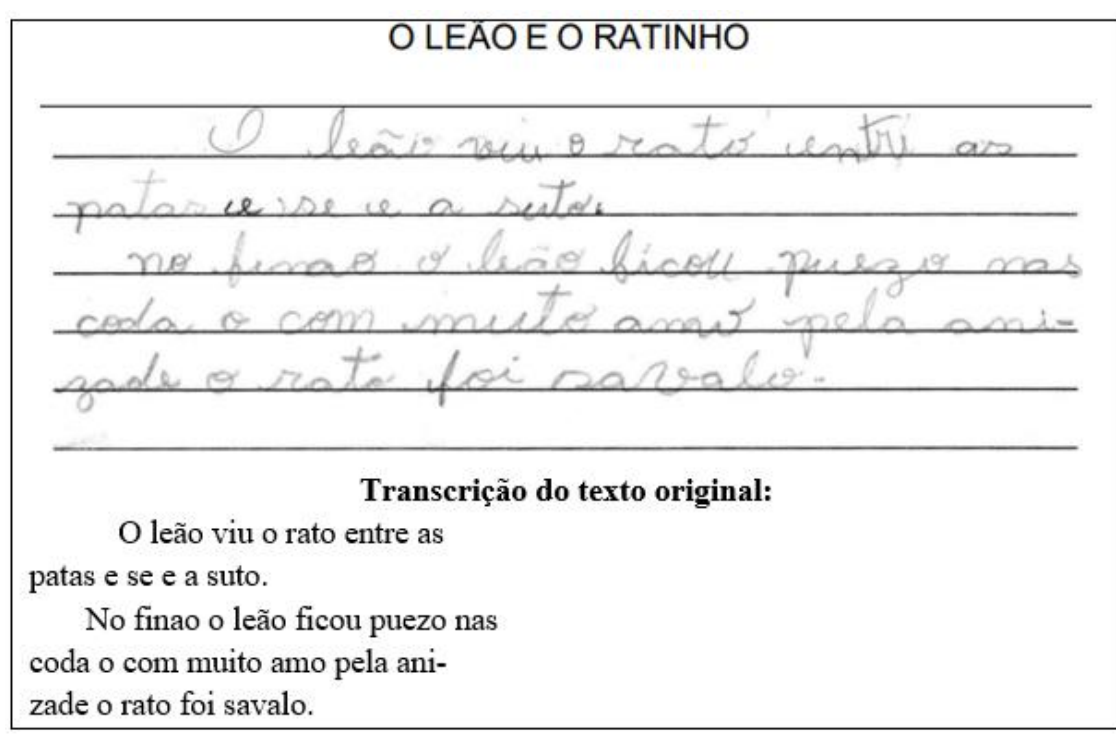

Fonte: Autoras (2021).

\subsection{Descrição da Oficina de reescrita}

Nesta oficina foi realizada a reescrita do texto, após revisão orientada por nós, os participantes, de acordo com os apontamentos deixados em forma de bilhetes abaixo do texto, fizeram a reescrita de sua história. No texto revisado, os familiares foram orientados a ler os apontamentos, questionamentos e comentários deixado pela pesquisadora, para orientar a criança em relação ao comando de produção.

O participante 1 no bilhete orientador foi solicitado que reescrevesse um trecho da história, corrigisse três palavras com erros ortográficos (algum, caçadores, conseguiu), acrescentasse no final de seu texto a moral da história. Na sua reescrita fez o uso da paragrafação, acrescentou pontuação no seu texto e fez a correção das palavras indicadas pela professora, mas apenas a palavra "conseguiu", que na reescrita permaneceu com a troca $\mathrm{M} / \mathrm{N}$. Observamos, assim, que o texto nunca é um trabalho encerrado, pois, ao revisar, o autor reformula o texto quantas vezes for necessário (Menegassi, 2016).

Ele fez a correção de ortografia das palavras "algum" e "caçadores" buscando, possivelmente, na memória informações que possibilitaram organizar seu texto, estruturando-o com começo, meio e fim. Isso pode ser observado na etapa de reescrita do seu texto. Ao fazer uma cópia da fábula, na etapa de reescrita, suas reformulações foram executadas além dos apontamentos sugeridos pela professora. Os apontamentos, embora breves e diretos, levaram a um nível de interação entre o professor e o aluno e entre o aluno e o texto e, consequentemente, permitiram que o aluno relesse e fizesse novas inserções de informações em seu texto com ajuda do comando de sugestões de melhorias que a professora enviou ao aluno auxiliado pelo seu responsável.

Essa oficina de reescrita, possivelmente, mobilizou as funções psicológicas superiores, em relação à linguagem, pois o participante acrescentou à moral da história, pensamentos próprios, o que Vygotsky (2007) caracteriza como o percurso da atividade social, interpsíquica, ou seja, as atividades realizadas coletivamente por meio da interação, relacionadas às propriedades internas do pensamento. 
Figura 6 - Produção textual do participante 1.

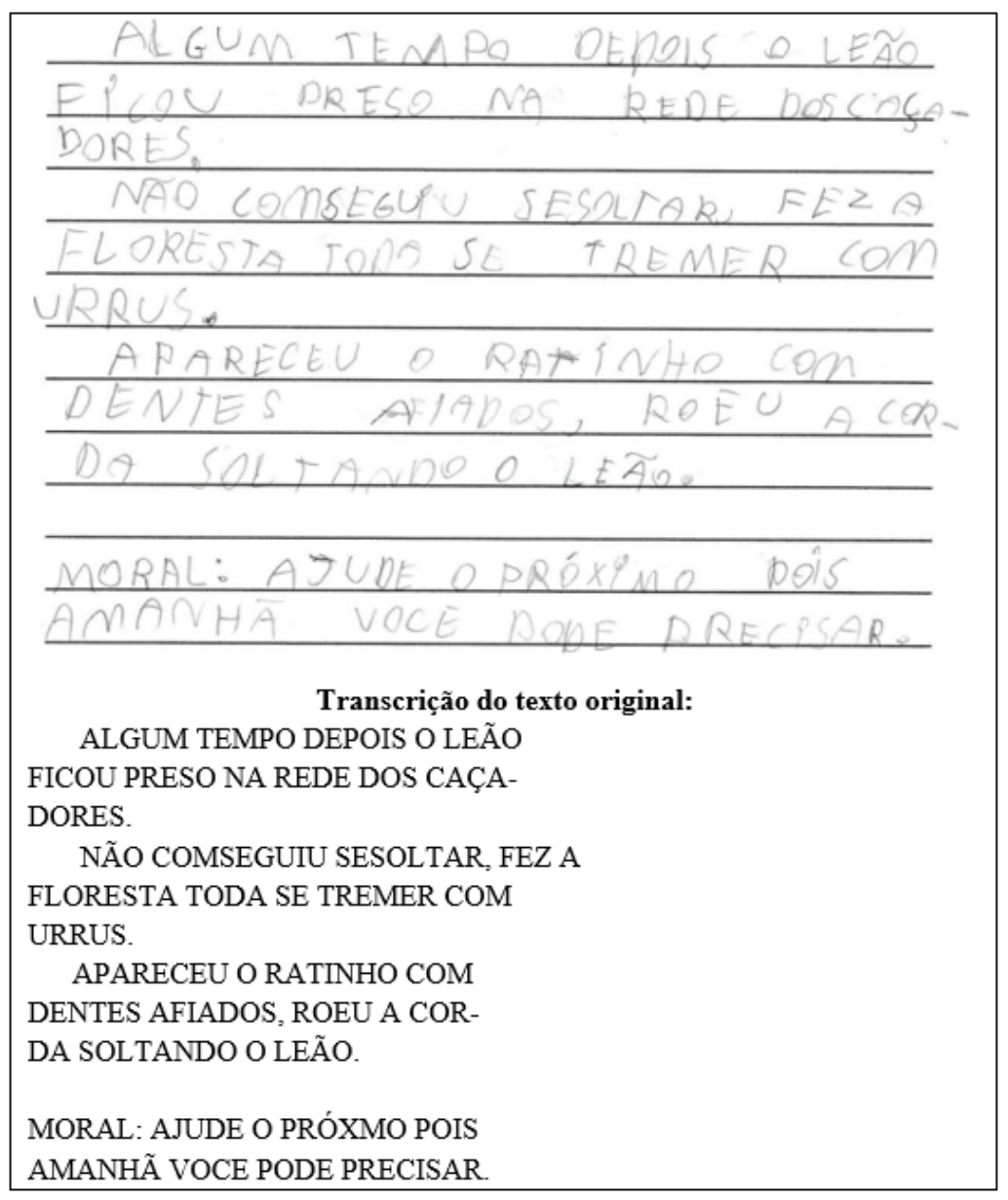

Fonte: Autoras (2021).

Para o participante 2, na etapa de revisão foi apontada a reescrita da parte inicial, com questionamentos e comentários de como iniciar sua história em substituição a expressão era uma vez. Fizemos indagações sobre o que o leão fazia quando apareceu o ratinho e pedimos que realizasse a correção ortográfica das palavras caçar, tanto e soltou.

O participante 2 reescreveu o texto conforme os apontamentos sugeridos. Deixou espaço do parágrafo para começar o texto e fez a correção das palavras caçar, tanto e soltou. Observamos acréscimo de informação no início do texto, onde descreveu como estava o leão, fez uso da vírgula e do ponto final. Fez o uso de letra maiúscula. Observamos que, apesar de sugerir reescrever apenas um trecho, a criança fez a revisão e reescrita de todo o texto, modificando partes de sua escrita inicial, fez a substituição de tempos verbais como rugindo/rugiu, sauvar ele/salvá lo. Assim, inferimos, que na reescrita do participante 2 , houve ajuda da família.

Além do que já foi exposto, a escrita do aluno demonstra a supressão da palavra "nervos", de sinais de pontuação (ponto final), bem como da conjunção ("e") e do pronome ("ele"), melhorar sua coerência textual. Na sequência, ele fez substituições desses elementos a partir das indicações e sugestões do professor /revisor, e de seu próprio processo de revisão, deixando seu texto com a coesão e com a coerência necessárias à compreensão do leitor (Menegassi, 2016).

Nesse aspecto de revisão e reescrita, Serafini (1998) ensina que o aluno estimulado a rever e a reescrever seu texto, compreende sobre as diferentes formas de se trabalhar para chegar a uma reescrita adequada. A reescrita não implicou apenas em reescrever o texto, mas ao entendimento que aluno teve em relação aos apontamentos feitos pela professora e da revisão do 
próprio sujeito ao retomar seu texto corrigido, o que possibilitou, ao professor, acompanhar o desenvolvimento e as habilidades específicas da escrita do aluno (Gasparotto, 2014).

Figura 7 - Produção textual do participante 2.

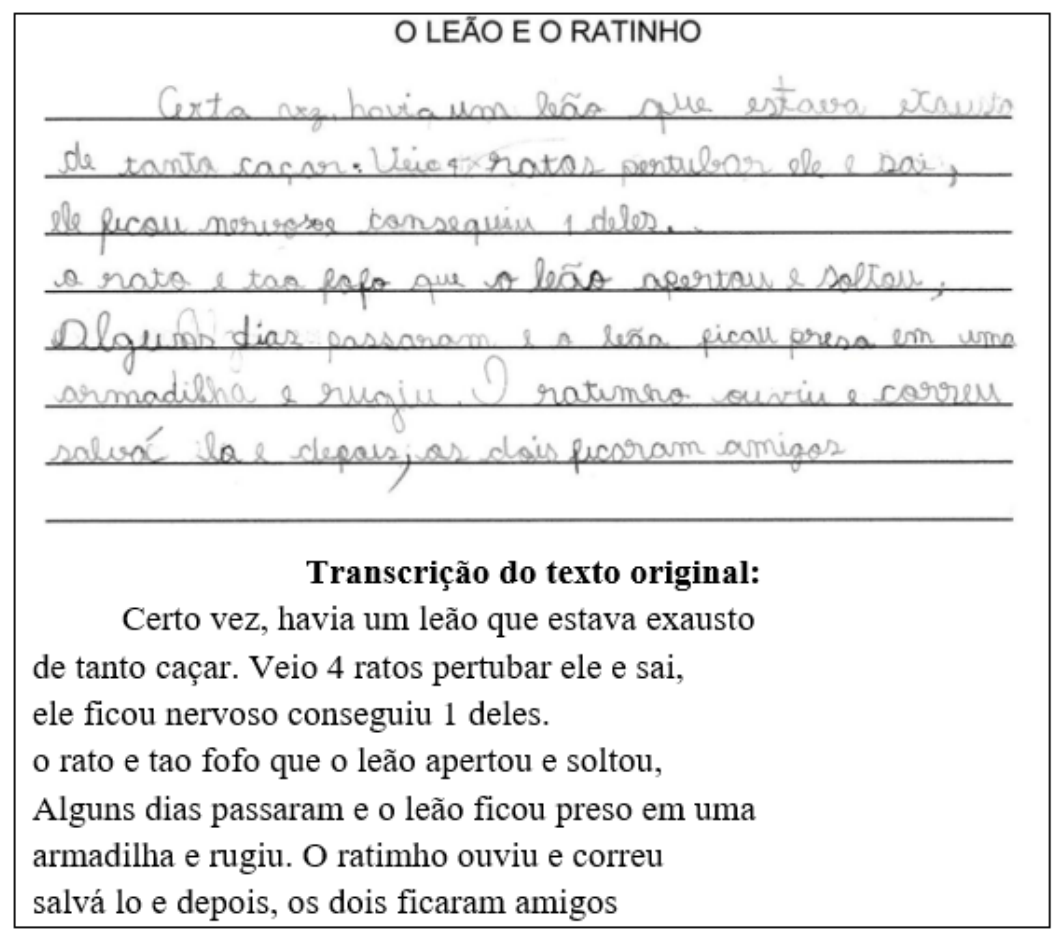

Fonte: Autoras (2021).

O participante 3 na etapa de revisão, fizemos apontamentos, questionamentos e comentários e indagamos o que o leão fazia quando apareceu o ratinho e como o ratinho ajudou o leão. Ademais, orientamos que escrevesse qual seria a moral dessa história. O participante reescreveu seu texto conforme os apontamentos feitos, ou seja, acrescentou informações, fez uso de pontuação e paragrafação e apresentou sequência de ideias, o que demonstra a mobilização das funções psicológicas superiores (atenção, memória e linguagem) no momento de reescrita.

No primeiro parágrafo, apresentou, com detalhes, o que o leão fazia quando apareceu o ratinho: ele escreveu que o leão estava dormindo e o ratinho ficou brincando na frente dele, quando o leão acordou e pisou no ratinho. Além disso, o aluno demonstrou sequência de ideias, descreveu o conflito do ratinho quando é pego pelo leão e acrescentou o sentimento do leão em relação ao ratinho (o leão ficou com pena do ratinho e deixou ele ir embora).

Em outro parágrafo, o estudante escreveu o conflito vivenciado pelo leão e a ajuda do ratinho ao roer a rede, acrescentando informações inferenciais dizendo que eles ficaram amigos. Ainda, utilizou informações de atividades anteriores para acrescentar a moral da história: "Com isso aprendemos que devemos ajudar os outros". O participante possivelmente na reescrita, foi estimulado por seus familiares a direcionar a atenção e acrescentar dados estruturais ao seu texto, além de buscar, em sua memória, informações referentes aos acontecimentos ocorridos no início da fábula.

Ademais, o aluno reconheceu o problema existente na história, bem como citou o desfecho e moral da fábula. Dessa forma, segundo Menegassi (2010), a produção de escrita como trabalho organizado, pensado, interativo, dialógico e produtivo conduzem o aluno à atenção de características específicas do texto, contribuindo para associações armazenadas na memória para organizar o pensamento e executar o texto escrito, atendendo à finalidade comunicativa da interlocução. 
Além disso, o processo de desenvolvimento das funções psicológicas superiores e de novas formas de transformações cognitivas não ocorre de forma passiva e individual, mas sim como um processo ativo de interação entre autor e interlocutor, pois está relacionado com as formas de mediação social pelos signos e pelo outro (Smolka \& Góes, 2008).

Nesse sentido, tratando-se de ensino remoto no qual os alunos eram auxiliados por familiares, os apontamentos solicitados no processo de reescrita possibilitaram o professor mediar e direcionar a escrita da criança, organizando seu pensamento, a fim de operar sobre a escrita, reorganizar e redigir o trabalho simbólico, delineando aquilo que está em proces so de apropriação na criança (Vygostky, 2007).

A reescrita o aluno/autor adicionou elementos e informações no texto ora para esclarecer, ora para completar informações que não foram integralmente apresentadas ao leitor (Menegassi, 2016). O participante 3 reescreveu seu texto conforme os apontamentos feitos por nós, ou seja, acrescentou informações, fez uso de pontuação e paragrafação e apresentou sequência de ideias, o que demonstra a mobilização das funções psicológicas superiores (atenção, memória e linguagem) no momento de reescrita. É provável que na reescrita foi estimulado por seus familiares a direcionar a atenção e acrescentar dados estruturais ao seu texto, além de buscar, em sua memória, informações referentes aos acontecimentos ocorridos no início da fábula.

Figura 8 - Produção textual do participante 3.

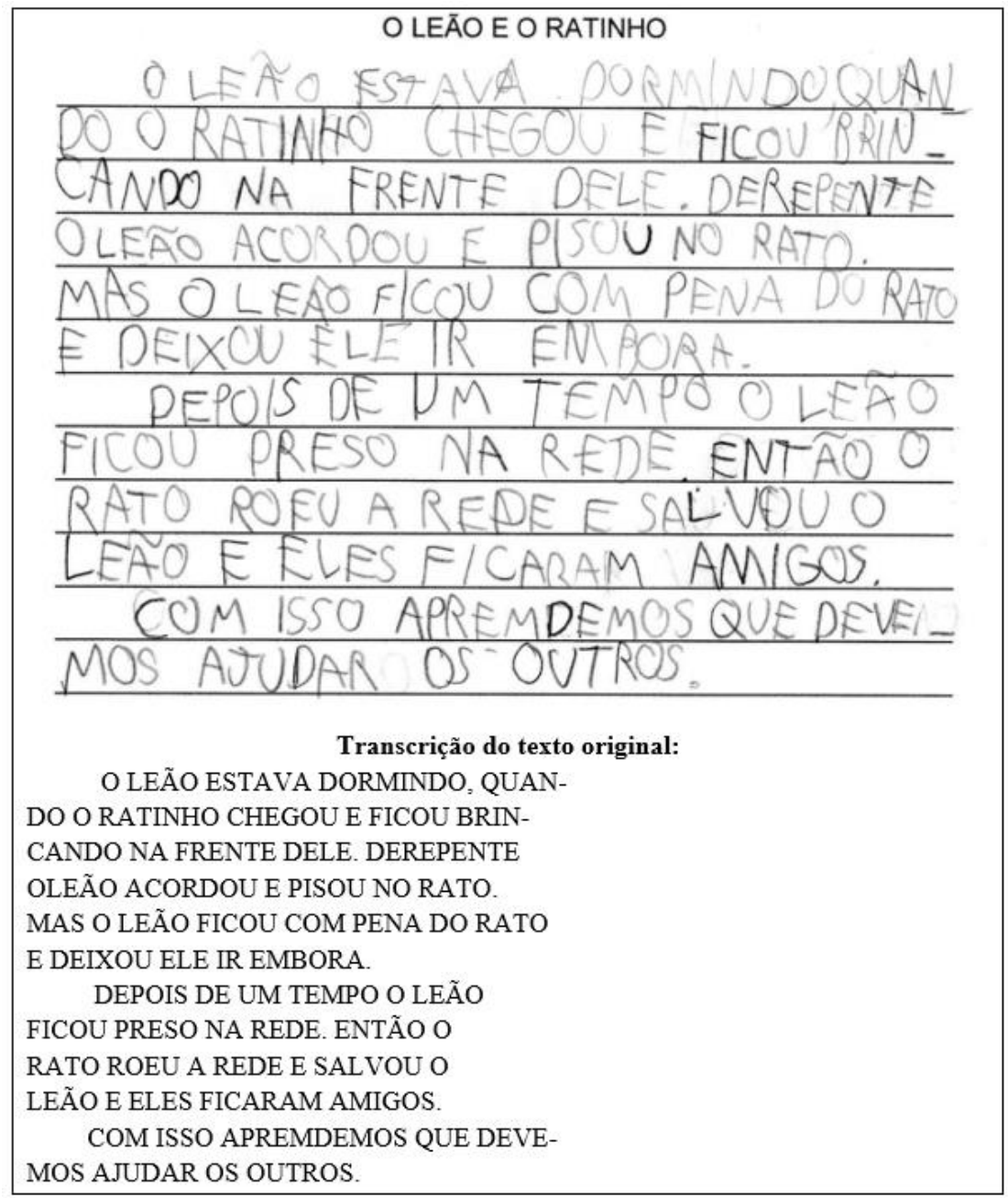

Fonte: Autoras (2021). 
O participante 4 não fez a devolutiva da reescrita do texto e o participante 5 não realizou a reescrita do texto. Visto que os participantes 4 e 5 apresentam Transtorno do Déficit de Atenção e Hiperatividade (TDAH), estudos evidenciam de uma forma geral, que crianças com TDAH apresentam desempenho inferior em tarefas mais complexas, na decodificação leitora, nas tarefas metalinguísticas, especialmente em exercícios que demandam mais concentração, retenção de informações, análise e revisão de informações (Santos et al, 2021 \& Pedroso et al., 2021).

Desta forma os resultados da escrita e da reescrita não foram os esperados, pelo fato de haver algumas limitações do ensino remoto como a falta da presença do professor para mediar e interagir durante a realização das atividades propostas, inviabilizando avanços nas produções textuais dos alunos. Embora a família tenha se esforçado na hora de auxiliar o filho nas tarefas escolares, na maioria das vezes, não conseguiram atender as exigências.

\section{Considerações Finais}

Em partes a pesquisa confirmou nosso objetivo que as funções psicológicas superiores próprias dos humanos se desenvolvem quando há a interação da criança com outro sujeito mais experiente. Ao redigir a nova versão de seu texto, os participantes mobilizaram a atenção voluntária e a memória lógica para melhorar a linguagem escrita de seu texto, deixando-o mais coerente.

Fica evidente que a figura do professor no momento de mediar o conhecimento é insubstituível, pois muitas dúvidas acerca da interpretação textual e produção da escrita poderiam ter sido sanadas se estivéssemos no presencial pois ao fazer as inferências adequadas possibilitariam uma reflexão que auxiliaria os sujeitos com dificuldades de aprendizagem e Transtorno do Déficit de Atenção e Hiperatividade (TDAH), no processo da escrita. E embora os familiares demonstraram compromisso em auxiliar os filhos nos estudos, em nossa pesquisa constatamos por meio de questionário enviados aos pais que em sua maioria não apresentavam formação de ensino superior.

A luz dessas considerações, por meio da análise e da reflexão dos resultados dos trabalhos desenvolvidos pelos cinco participantes nos permitem afirmar que, mesmo sendo menos do que esperávamos, as intervenções possibilitaram, aos participantes dessa pesquisa, o desenvolvimento de funções psicológicas superiores como a atenção, a linguagem e a memória. Identificamos ainda, em relação aos aspectos linguísticos e textuais assimilados pelos participantes com dificuldade de aprendizagem, na etapa de revisão e reescrita, três sujeitos demonstraram assimilar alguns aspectos que precisavam ser aprimorados no texto original como, por exemplo, estrutura textual, correções ortográficas, uso adequado da pontuação e paragrafação.

Na oficina de produção textual, constatamos que os participantes 3 e 5 que têm diagnóstico de TDAH demonstraram em suas produções que conhecem o contexto da fábula, mas, por apresentarem TDAH, foi possível perceber que por meio da escrita desses participantes a atenção deles se limitou a escrever de forma sucinta, decorrente da dificuldade em manter o foco, o que pode ter interferido na realização de suas produções textuais.

Isso demonstra as fragilidades do ensino remoto, pois, se o ensino fosse presencial, o professor faria a mediação no momento da realização das atividades, atuaria na zona de desenvolvimento proximal e mobilizaria a atenção voluntária para ampliar a escrita do aluno (Vygotsky; Luria, 1996). Além disso, a mediação adequada, junto aos alunos com TDAH, contribuiria para o desenvolvimento e aprendizagem, pois redimensionaria aquilo que as funções primitivas não conseguem realizar, para as funções superiores como a memória cultural, a atenção voluntária e a linguagem. Assim, os sujeitos teriam melhores resultados em sua produção (Tuleski \& Eidt, 2007).

Podemos concluir que as reflexões e análises dos resultados dos trabalhos desenvolvidos pelos alunos nos permite afirmar que, mesmo sendo menos do que esperávamos, as intervenções possibilitaram, aos sujeitos, o desenvolvimento de 
Funções psicológicas superiores como a atenção, a memória e a linguagem. Porém algumas limitações do ensino remoto, como a falta da presença do professor para mediar e interagir durante a realização das atividades propostas, inviabilizaram avanços nas produções textuais dos sujeitos.

Dada a relevância dessa pesquisa, evidenciamos que o ensino remoto não pode se equivaler ao ensino presencial. Como salienta Vygotsky (2007), o bom ensino é aquele que antecede ao desenvolvimento, portanto se constitui nas relações interpessoais, sendo fundamental, nesse processo, a presença e a interação simultânea do professor e do aluno. Como investigação futura e colaborativa com os docentes, sugerimos a continuidade desse estudo, junto às séries iniciais do Ensino Fundamental, na forma de ensino presencial, a fim de verificar sua efetivação em contexto de ensino e aprendizagem, a pontuar e comparar suas limitações e possibilidades de ampliação.

\section{Referências}

Beloti, A. (2016). A formação teórica, metodológica e prática dos conceitos de revisão e reescrita no PIBID de língua portuguesa. Tese (Doutorado em Letras) Programa de Pós-Graduação em Letras, Universidade Estadual de Maringá. http://repositorio.uem.br:8080/jspui/handle/1/4116.

Benczik, E. B. P. (2000). Transtorno de Déficit de Atenção /Hiperatividade: Atualização diagnóstica e terapêutica. São Paulo: Casa do Psicólogo.

Fiad, R. S. (2006). Escrever é reescrever. 1 , (Coleção Alfabetização e Ceale/FaE/UFMG. https://orientaeducacao.files.wordpress.com/2017/02/col-alf-let-11-escrever_reescrever.pdf

Fiad, R. S., \& Mayrink-Sabinson, M. L. T. (2001). A escrita como trabalho. In: Martins, M. H. (Org.). Questões de linguagem. (6a ed.). Contexto.

Garcez, L. H. do C. (1998). A escrita e o outro: os modos de participação na construção do texto. UnB.

Gasparotto, D. M. (2014). O trabalho colaborativo em práticas de revisão e reescrita de textos em séries finais do ensino fundamental I. Dissertação (Mestrado em Letras) Programa de Pós-Graduação em Letras, Universidade Estadual de Maringá. http://www.ple.uem.br/defesas/pdf/dmgasparotto.PDF.

Geraldi, J. W. (1996). Linguagem e Ensino: exercícios de militância e divulgação. Mercado de Letras.

Leontiev, A. N. et al. (2005). Psicologia e Pedagogia: bases psicológicas da aprendizagem e do desenvolvimento. Tradução de Rubens Eduardo Fria. São Paulo: Centauro.

Luria, A. R. (1992). A construção da mente. Tradução de Marcelo Brandão Cipolla. Ícone.

Luria, A. R. (1981). Fundamentos de Neuropsicologia. Tradução de Juarez Aranha Ricardo. Rio de Janeiro: Livros Técnicos e Científicos. Universidade de São Paulo.

Menegassi, R. J. (2016). A escrita como trabalho na sala de aula. In: Jordão, C. M. (Org.). A linguística aplicada no Brasil: rumos e passagens. Campinas: Pontes.

Menegassi, R. J. (2010). O processo de produção textual. In: Santos, A. R. dos, Grego, E. A., \& Guimarães, T. B. (Org). A produção textual e o ensino. Eduem.

Menegassi, R. J., \& Gasparotto, D. M. (2019). Revisão dialógica: princípios teórico-metodológicos. Linguagem em (Dis)curso. 19(1). https://www.scielo.br/j/ld/a/NSsvV7jRqF9nxSkcnxrv8bR/?format=pdf\&lang=pt.

Menegassi, R. J., \& Gasparotto, D. M. (2020). As práticas de revisão textual-interativa: apontamento, questionamento e comentário. In: Fuza, A. F. et al. (Orgs.). Interação e escrita no ensino de língua. Campinas, SP: Pontes Editores.

Pedroso, L. V. [et al.]. (2021). A influência do Transtorno do Déficit de Atenção e Hiperatividade (TDAH) no aprendizado de crianças: uma revisão integrativa da literatura. Research, Society and Development, 10, 7, e16610716354.

Santos, L. S. [et al.]. (2021). Desempenho em atividades de escrita em escolares com dificuldades em habilidades sociais e/ou alterações comportamentais. Research, Society and Development, 10, 14, e176101421885.

Serafini, M. T. (1998). Como escrever textos. (9a ed.). Globo.

Sercundes, M. M. I. (2004). Ensinando a escrever: as práticas em sala de aula. In: Geraldi, J. W., \& Citelli, B. (Coords.). Aprender e ensinar com textos de alunos. (7. ed.). São Paulo: Cortez.

Smolka, A. L. B., \& Góes, M. C. R. de (2008). A linguagem e o outro no espaço escolar: Vygotsky e a construção do conhecimento. (3a ed.). Papirus.

Tuleski, S. C., \& Eidt, N. M. (2007). Repensando os distúrbios de aprendizagem a partir da psicologia histórico-cultural. Psicologia em estudo. 12(3).

Vigotsky, L. S., Luria, A. R., \& Leontiev, A. N. (2010). Linguagem, desenvolvimento e aprendizagem. (11a ed.). Ícone.

Vygotsky, L. S. (2001). Obras Escogidas: problemas de Psicologia Geral. Tomo II. Tradução de José Maria Bravo. (2a ed.). Machado. 
Research, Society and Development, v. 11, n. 3, e22111326385, 2022

(CC BY 4.0) | ISSN 2525-3409 | DOI: http://dx.doi.org/10.33448/rsd-v11i3.26385

Vygotsky, L. S. (2007). A formação social da mente. (7a ed.), Coleção Psicologia e Pedagogia. Martins Fontes.

Vygotsky, L. S. (1988). Pensamento e linguagem. Martins Fontes.

Vygotsky, L. S., \& Luria, A. R. (1996). Estudos sobre a história do comportamento: símios, homem primitivo e criança. Artes Médicas.

Yin, R. K. (2001). Estudo de caso: planejamento e métodos. (2a ed.). Bookman. https://saudeglobaldotorg1.files.wordpress.com/2014/02/yinmetodologia_da_pesquisa_estudo_de_caso_yin.pdf. 